denses de origen africano presentan menores tasas de incidencia de cáncer que las mujeres blancas, su tasa de mortalidad por cáncer es $20 \%$ mayor. Las tasas de mortalidad por cáncer de estómago y cervicouterino entre las estadounidenses de origen africano es más del doble de la observada en mujeres blancas de ese país. Esto puede deberse a una mayor exposición de aquellas a los factores de riego. En el caso particular del cáncer de mama, las estadounidenses blancas tienen una mayor tasa de incidencia que las de origen africano, posiblemente debido a la combinación de diferentes factores, entre ellos que las mujeres blancas se someten a mamografías con mayor frecuencia, tienen sus embarazos a mayor edad y usan más tratamientos de reemplazo hormonal. Las tasas de incidencia y mortalidad en otros grupos raciales y étnicos son inferiores a las que presentan los estadounidenses blancos y de origen africano, excepto en el caso del cáncer cervicouterino, gástrico y hepático.

La probabilidad de sufrir de cáncer en algún momento durante la vida es mayor entre los hombres (45\%) que entre las mujeres (38\%). Sin embargo, debido a la frecuencia del cáncer de mama, las mujeres presentan una probabilidad ligeramente mayor que los hombres de sufrir un cáncer antes de los 60 años de edad.

Las tasas de supervivencia una vez diagnosticado el cáncer son menores entre hombres y mujeres de origen africano que entre los otros grupos; el diagnóstico de cáncer en estadios tempranos es menos frecuente entre los descendientes de africanos que entre la población blanca. Además, los estadounidenses de origen africano, al igual que las personas de origen hispano, tienen una menor tasa de supervivencia a los cinco años de diagnosticada la enfermedad que los blancos, independientemente del estadio en el momento del diagnóstico, lo cual puede indicar que hay disparidad en el acceso de estos grupos a una atención médica de buena calidad y en la presencia simultánea de trastornos distintos del cáncer. Las personas que pertenecen a poblaciones minoritarias tienen una mayor probabilidad que la que las de raza blanca de recibir un diagnóstico de cáncer en estadio avanzado.

Después de los accidentes, el cáncer es la segunda causa más importante de muerte en niños de 1 a 14 años en los EUA. Los tipos de cáncer más frecuentes en estos niños son la leucemia (especialmente la leucemia linfocítica aguda), los tumores del sistema nervioso central y del sistema simpático, los linfomas, los sarcomas de tejidos blandos y los tumores renales. La tasa de supervivencia relativa en los niños a los cinco años de diagnosticada la enfermedad ha mejorado significativamente en los últimos 25 años para muchos tipos de cáncer, entre ellos el linfoma no hodgkiniano, la leucemia linfocítica aguda, la leucemia mieloide aguda y el tumor de
Wilms. La tasa de supervivencia relativa a los cinco años de diagnosticada la enfermedad en niños con cáncer en cualquier parte del organismo mejoró de $56 \%$ en los pacientes diagnosticados entre 1974 y 1976, a 78\% en los diagnosticados entre 1992 y 1999.

Las cifras estimadas aportadas por la Sociedad Estadounidense del Cáncer permiten conocer los patrones actuales de incidencia y mortalidad por cáncer en los EUA. Estos valores tienen la finalidad de ayudar a perfilar los esfuerzos emprendidos para reducir el peso del cáncer en la salud pública, pero no deben utilizarse para seguir la incidencia y la mortalidad anuales. (Jemal A, Tiwari RC, Murray T, Ghafoor A, Samuels A, Ward E, et al. Cancer Statistics, 2004. CA Cancer J Clin. 2004; 54:8-29. Puede encontrarse en: http://caonline. amcancersoc.org/cgi/content/full/54/1/8 Acceso el 15 de febrero de 2004.)

\section{Método de detección viral comparado con la prueba citológica periódica para el tamizaje de mujeres}

El objetivo principal del tamizaje citológico mediante la prueba de Papanicolaou es identificar a las mujeres con lesiones cervicouterinas que conllevan un mayor riesgo de desarrollar cáncer cervicouterino. Estas mujeres deben recibir seguimiento y tratamiento adecuados para evitar la progresión hacia un cáncer invasor. Los expertos coinciden en opinar que las mujeres con lesiones citológicas avanzadas en el cuello uterino se deben remitir inmediatamente para un estudio más profundo; no obstante, todavía se discute cómo se debe proceder con las mujeres que presentan lesiones citológicas de escasa malignidad.

Los resultados obtenidos hasta el momento acerca del papel etiológico que desempeña la infección por virus del papiloma humano (VPH) en el desarrollo del cáncer cervicouterino y de las neoplasias intraepiteliales cervicouterinas indican que la prueba de detección de VPH se puede utilizar como método de tamizaje para identificar a las mujeres en mayor riesgo de desarrollar cáncer cervicouterino y que, por lo tanto, deben ser remitidas para un examen por colposcopia. Sin embargo, los resultados acerca de la utilidad del tamizaje por VPH en mujeres con resultados citológicos indefinidos son contradictorios.

Se realizó un metaanálisis para analizar toda la información disponible en la literatura científica acerca de la exactitud diagnóstica de la prueba detectora de infección por VPH. Se tomaron los datos de los artículos publicados entre 1992 y 2002 que describieran los resultados de las pruebas virológicas y citológicas seguidas de biopsias guiadas me- 
diante colposcopia en mujeres que en su primer análisis hubieran presentado en el frotis células atípicas de significado indeterminado (CASI). En total, 17 artículos informaban de los resultados de 15 estudios que cumplían con los criterios de inclusión y en los cuales estaban documentados tanto el tamizaje por VPH como los resultados histológicos (presencia o ausencia de neoplasia intraepitelial cervicouterina de grado II en adelante). Se encontraron también 18 estudios en los que se documentaba la exactitud de las pruebas citológicas periódicas; en 9 de ellos la línea de corte para detectar resultados citológicos alterados se encontraba en el umbral de CASI o por encima; en 7 se encontraron lesiones intraepiteliales escamosas de baja malignidad (LIEB) o más graves y en 2 las lesiones intraepiteliales escamosas eran avanzadas (LIEA) o más graves. Se emplearon modelos de efectos aleatorios para agrupar los parámetros de exactitud en los casos en que se observó heterogeneidad entre los estudios. Las diferencias en la exactitud se evaluaron mediante el agrupamiento de las razones de la sensibilidad (o de la especificidad) de las pruebas detectoras de VPH frente a las de estudios citológicos periódicos.

En total, 5454 mujeres habían presentado CASI y se conocían los resultados de sus pruebas detectoras de ácido desoxirribonucleico (ADN) de VPH. Nueve estudios eran pequeños, con menos de 200 mujeres cada uno, cuatro de los estudios tuvieron 200-500 mujeres, y en dos estudios participaron más de 500 mujeres. El Estudio de Tamizaje CASILIEB (ASCUS-LSIL Triage Study, conocido como ALTS) aportó más de 2300 mujeres.

El metaanálisis de los resultados de todas las pruebas de VPH reveló una sensibilidad global de $84,4 \%$ (intervalo de confianza de $95 \%$ [IC95\%]: $77,6 \%$ a $91,1 \%$ ) y una especificidad de $72,9 \%$ (CI95\%: $62,5 \%$ a $83,3 \%)$. Al considerar solo los ocho estudios en los que se utilizó el ensayo Hybrid Capture II para la detección de los tipos de VPH de alto riesgo se encontró una sensibilidad global de 94,8\% (IC95\%: 92,7\% a 96,9\%) y una especificidad de $67,3 \%$ (IC95\%: $58,2 \%$ a $76,4 \%$ ).

La sensibilidad y especificidad de las pruebas citológicas periódicas con CASI en la línea de corte o por encima de ella fueron de 81,8\% (IC95\%: 73,5\% a $84,3 \%$ ) y $57,6 \%$ (IC95\%: $49,5 \%$ a $65,7 \%$ ), respectivamente. En cambio, la sensibilidad y la especificidad de las pruebas citológicas periódicas con LIEB en la línea de corte o por encima de ella fueron de $45,7 \%$ (IC95\%: $34,0 \%$ a $57,4 \%$ ) y de $89,1 \%$ (IC95\%: $82,1 \%$ a $96,2 \%)$, respectivamente.
La razón dada por la sensibilidad global del ensayo Hybrid Capture II dividida entre la sensibilidad de la prueba citológica periódica cuando las CASI estaban en la línea de corte o por encima de ella según cuatro estudios que evaluaron ambos métodos de tamizaje fue de 1,16 (IC95\%: 1,04 a $1,29)$, lo que indica que la sensibilidad global del ensayo Hybrid Capture II fue en estos casos significativamente mayor que el de la prueba citológica repetida. La especificidad global de este ensayo fue también superior, pero la diferencia no fue estadísticamente significativa (1,05; IC95\%: 0,96 a 1,15). Al comparar por separado el ensayo Hybrid Capture II con la prueba citológica periódica cuando los valores de LIEB y LIEA se encontraban en la línea de corte o por encima de ella, las razones de sensibilidad fueron de 1,69 (IC95\%: 1,54 a 1,85) y de 2,80 (IC95\%: 2,43 a 3,31), respectivamente, mientras que las razones de especificidad de ambas pruebas fueron de 0,71 (IC95\%: 0,64 a 0,80) y de 0,57 (IC95\%: $0,44$ a 0,74$)$, respectivamente.

Este metaanálisis parece corroborar las conclusiones del estudio ALTS. A fin de investigar si la diferencia en la sensibilidad de la prueba citológica periódica y la del ensayo Hybrid Capture II se veía afectada por los resultados del estudio ALTS, se repitió el metaanálisis sin incluir los resultados de ese estudio. La razón de sensibilidad global en los tres estudios restantes fue de 1,18 (IC95\%: 1,03 a 1,36) y la razón de especificidad global, de 1,03 (IC95\%: 0,89 a 1,19). De esta forma, la inclusión de los datos del estudio ALTS no afectó a los valores globales de exactitud relativa.

En conclusión, la sensibilidad cruzada del ensayo Hybrid Capture II para detectar el riesgo de sufrir neoplasias intraepiteliales cervicouterinas avanzadas en mujeres con resultados indeterminados en sus pruebas citológicas fue superior a la de la prueba repetida de Papanicolaou cuando los valores de CASI estaban en la línea de corte o por encima de ella. La especificidad de ambos métodos de tamizaje fue baja. El tamizaje citológico de mujeres con CASI usando valores de corte citológico más elevados ofrece una sensibilidad demasiado baja. Por lo tanto, el ensayo de detección de ADN de VPH (Hybrid Capture II) resultó superior como método de tamizaje que la prueba citológica periódica en mujeres con CASI. (Arbyn M, Buntinx F, Van Ranst M, Paraskevaidis E, Martin-Hirsch P, Dillner J. Virologic versus cytologic triage of women with equivocal pap smears: a meta-analysis of the accuracy to detect high-grade intraepithelial neoplasia. J Nat Cancer Inst. 2004;96:280-93). 